\title{
Factors Influencing on Peaceful Co-Existence: Christian's Living in Tehran
}

\author{
Mirzaei Farahnaz*, Hassan Ali Kadivar Zare, Sabzalizadeh Tayebeh \\ Department Educational Leadership, University of Malaya, Kuala Lumpur, Malaysia \\ Email: *fmirzaei42@yahoo.com
}

How to cite this paper: Mirzaei Farahnaz, Hassan Ali Kadivar Zare, Sabzalizadeh Tayebeh (2017) Factors Influencing on Peaceful Co-Existence: Christian's Living in Tehran. Open Access Library Journal, 4: e2384.

https://doi.org/10.4236/oalib.1102384

Received: January 14, 2016

Accepted: April 30, 2017

Published: May 3, 2017

Copyright ( 2017 by authors and Open Access Library Inc.

This work is licensed under the Creative Commons Attribution International License (CC BY 4.0).

http://creativecommons.org/licenses/by/4.0/

\begin{abstract}
Human being is the social creature and they are obliged to have the relationship together for continuing the merry and desirable life. This article implies to Christian minorities living in Tehran. Researchers have carried out the statistical analysis of SPSS software to show the factors influencing on peaceful co-existence in Christian minorities regarding to the religious, social, scientific culture and economic spheres. Various tables and figures have shown the significant results in the related friendship, altruism and mutual respect in study community. Over more, their satisfactions are classified into six remarkable priorities. Findings are considerable in all aspects of their daily life activities. It is concluded they have civil rights as well as other accepted legal ethnic groups. Investigators suggest more tolerance and harmony among different religious followers in all dimensions of society.
\end{abstract}

\section{Subject Areas}

Sociology

\section{Keywords}

Peaceful Co-Existence, Statistical Analysis, Essence, Society, Christian

\section{Introduction}

One of substantial issues in the contemporary world is to have strong social interaction and respect each other rights [1]. Various religious followers are living in a society with different interfaith thought [2]. Tehran has a few religious followers and they live calmly together. One of them is Christian minorities in some spheres of the capital of Iran. Researchers have paid much attention to all dimensions of Christian minorities living such as: peaceful co-existence in religious, society, scientific culture, economic and Jihad spheres. Although many 
books and articles were published about this topic during past years, all dimensions were not considered [3]. Investigators have gone to many churches with the legal authorization of the Islamic guidance and culture ministry of Islamic republic of Iran. This work has been done according to the most popular scholars in statistics. Cronbach's alpha method for measuring the reliability questionnaire was used in this work. Also, this study has been carried out based on Kolmogorov-Smirnov analytical methods. Adequacy of the sample size and questionnaire was examined by Bartlett's test. The findings were well suited in all priorities. In general, the conclusions highlight the maximum satisfactory in all aspects.

\subsection{Peaceful Co-Existence in Islam}

It would be expected that the people of the followers of the two major accepted Abrahamic faiths, Islam and Christianity, account for over half of the humanity inhabitants, which is a high percentage and is reflected in the mass media concerning faith to Islam and Christianity [4]. This article debates the peaceful co-existence in the faith by considering the recollection path to support acceptance and peaceful co-existence arrange by the faith so as to give out the guidance for the truthful and be alive jointly in the calm with their brothers. Opposing to the mentions in some accommodation that Islam was comprehensive to other faiths and 1st adherents, the faith might be considered as the best understanding religion on the level of the world. Badawi, receives this situation as soon as he is writing: like a sacred faith, original Islam is not equal with the proceedings of its "adherents" [5]. Similar to extra faiths, adherents or contend adherents are unsatisfactory, unsound creatures. More over when their works conform in different grades, to the original trainings of their religion. Other than there would be opportunity when their works are either self-governing or in disobedience of any original trainings. Foreigners can observe these criminal works like element the performance of religion. Occasionally, these works are dedicated, wrongly, as titled of religion. These assertions are considered as a consequence of unawareness, "honest" misunderstanding or still purposeful misunderstandings that are planned to supply authorize and ability designed for any practices [6]. To assess if an agreed practice or quarrel reconcile to the original trainings of a known faith or not, there should be a few circumstances for any assessments, as the narration of different faith societies is complete through deviation and flourishing achievement of the rule of their religions. Person achievements or defeats are not equal through perfect rule. Investigators are studying according to statistical analysis SPSS software throughout this research and are obtaining comprehensive findings.

\subsection{Islamic Human Rights Are Innate}

One of the characteristics of Islamic human rights is that these rights are based on human's nature; this nature is common among all humans. Some parts of Islamic duties and responsibilities are related to Muslims and believers, such as: prayer and fasting; Qur'an and traditions refer to these person in this manner 
(Q2: 178) and like that. Although all humans are bound to this religion, at first they need to adhere to monotheism and prophet hood and then these orders address them. Some orders are depend on human's compassion, not on his faith, such as: observance of justice, respect to elders, and also Islamic human rights, therefore, right of existence, right of kindness, right of learning, right of responsible freedom.

Although the basis of the first Islamic rights is religious will of God, which was sent by an inspiration and we can get it either by the prophet or by Imams or with right reason [7], but the religious will of God is based on justice. Soul of Qur'an ran and Islam is invitation to justice. Qur'an introduced establishment of: justice as one of the important objects of prophet's mission.

All of God's orders are based on justice:

And God never be unjust, neither in religion nor in creation, even doesn't he decide to: be unjust.

The basis of existence, either in creation or in legislation system, is based on justice: Our prophet said that and again he said that: "justice is God's scale on earth" [8].

\section{Methodology}

This article examines the effect of the statistical analysis of the datum. There is descriptive analysis of the datum; descriptive statistic sand suitable plots are examined. Inferential analysis is surveyed in this study. And seize test has examined to confirm or reject theories. In this investigation, 95 percent confidence level is assuming. It implies that five percent error in the computed outcomes expected. Data encryption: The first question that any form of like rites scored. Direct questions full agree $=5$, agree $=4$, neutral $=3$, disagree $=2$, fully disagree $=$ 1 is complete. Quantitative data have converted into numbers. Each item gathered from several questions. We calculate mean related questions that have coded.

Before statistical methods for the analysis is assume normal observations. They discussed as descriptive of normal likelihood plots and histograms. It studied statistics using the Kolmogorov-Smirnov test. If observations do not follow normal distribution, it would use nonparametric methods of statistical analysis. There are observation and analysis of statistical methods to confirm or deny theories such as: Kolmogorov Smirnov, one-sample T and Friedman.

\subsection{The Reliability of the Questionnaire}

Technical characteristics have reliability measurement tools [9]. It deals with learning. The instrument measures the extent to which the same conditions give the same outcomes. Among the definitions that have proposed for reliability can defined by Cybil and Frisky pointed out: "The correlation between one set and another set of scores. Which is a test that earned independently on a subject?"

Because this usually capacity coefficient ranges from zero (no correlation) to +1 (perfect correlation) changes. The reliability coefficient suggests the measuring 
instrument to measure to what extent. Characteristics of subjects with stable or variable feature is temporary measures it. The reliability coefficient measuring instrument is using in different ways. We can mention using Cronbach's alpha. In the following, we describe this method.

\subsection{Cronbach's Alpha Method for Measuring the Reliability Questionnaire}

This method is using to calculate the internal measurement tool. Such as questionnaires or tests measure different applies. In these, the answer to each question can have different values. Cronbach's alpha coefficient of variance $f$ the scores for each subset must ask (or the test) and calculate the total variance. The alpha coefficient is holding using the following formula.

$$
r_{1}=\frac{j}{j+1}\left(1-\frac{\sum s 2}{s 2}\right)
$$

In which: $j$ is number of questions on the questionnaire or test.

Variance test of $j=s_{j}^{2}$, Total variance test $=S 2$ The coefficient of zero indicates no reliability and $1+$ indicates complete reliability.

Typical values of 0.7 for this ratio can confirm the reliability of the questionnaire.

\subsection{Construct Validity and Adequacy of the Sample Size}

In order to assess the adequacy of the sample size and validity (factor analysis could be done), to arrange attest (Kaiser-Meyer-Olkin) KMO and Bartlett are used. KMO test, the test statistic is defined as follows:

$R$ : is the simple correlation coefficient between variables $I$ and $J$. And $A$ is minor correlation coefficient is between them.

The values are greater than 0.7 explain adequate sample size.

In this test the null hypothesis that the variables are correlated only with themselves. Reject the null hypothesis that the correlation matrix that contains meaningful information. There are minimum requirements for conducting factor analysis. And the $\mathrm{n}$ construct validity is confirmed.

\section{Presentation and Analysis of Outcomes about Christian's Living in Tehran}

In the first step, durability and reliability of the questionnaires are analyzed and the results are shown in Table 1.

According to the statistics, KMO (who is more than 0.6) the adequacy of the sample size can be verified. The significance level for the Bartlett test, factor analysis is confirmed. Due to the variables (significance level less than 0.05) construct validity is confirmed (Table 2).

Table 1. Adequacy of sample size and questionnaire (Bartlett's test).

\begin{tabular}{cccc}
\hline KMO statistic & Chi-square statistic & Degrees of freedom & Significance level \\
\hline 0.664 & 1146.237 & 561 & 0.000 \\
\hline
\end{tabular}




\subsection{The Assumption of Normality of Each Variable Descriptive (Histogram Plot)}

\subsubsection{Peaceful Co-Existence in Religion}

The assumption of normality related to Peaceful Co-Existence in Religion is shown in Figure 1.

\subsubsection{Peaceful Co-Existence in Society}

The assumption of normality related to Peaceful Co-Existence in Society is shown in Figure 2.

\subsubsection{Peaceful Co-Existence in Science}

The assumption of normality related to Peaceful Co-Existence in Science is shown in Figure 3.

\subsubsection{Peaceful Co-Existence in Economy}

The assumption of normality related to Peaceful Co-Existence in Economy is shown in Figure 4.

Table 2. Provide a descriptive analysis of the variables.

\begin{tabular}{cccccccc}
\hline & \multicolumn{7}{c}{ Descriptive analysis } \\
\hline Variable name & Number & Average & Mean & $\begin{array}{c}\text { Standard } \\
\text { deviation }\end{array}$ & $\begin{array}{c}\text { Minimum } \\
\text { value }\end{array}$ & $\begin{array}{c}\text { Maximum } \\
\text { value }\end{array}$ \\
\hline Peaceful co-existence in religion & 384 & 4.7835 & 5.0000 & 0.39030 & 3.50 & 5 \\
Peaceful co-existence in society & 384 & 4.8411 & 4.8667 & 0.11965 & 4.33 & 5 \\
Peaceful co-existence in science & 384 & 4.8411 & 5.0000 & 0.21210 & 3.80 & 5 \\
Peaceful co-existence in economy & 384 & 4.8531 & 5.0000 & 0.18869 & 4.20 & 5 \\
Peaceful co-existence in culture & 384 & 4.7682 & 4.8571 & 0.12649 & 4.29 & 5 \\
Peaceful co-existence in Jihad & 384 & 4.8344 & 5.0000 & 0.24417 & 3.75 & \\
Peaceful co-existence in life & 384 & 4.8189 & 4.8345 & 0.10606 & 4.45 & 4.98 \\
\hline
\end{tabular}

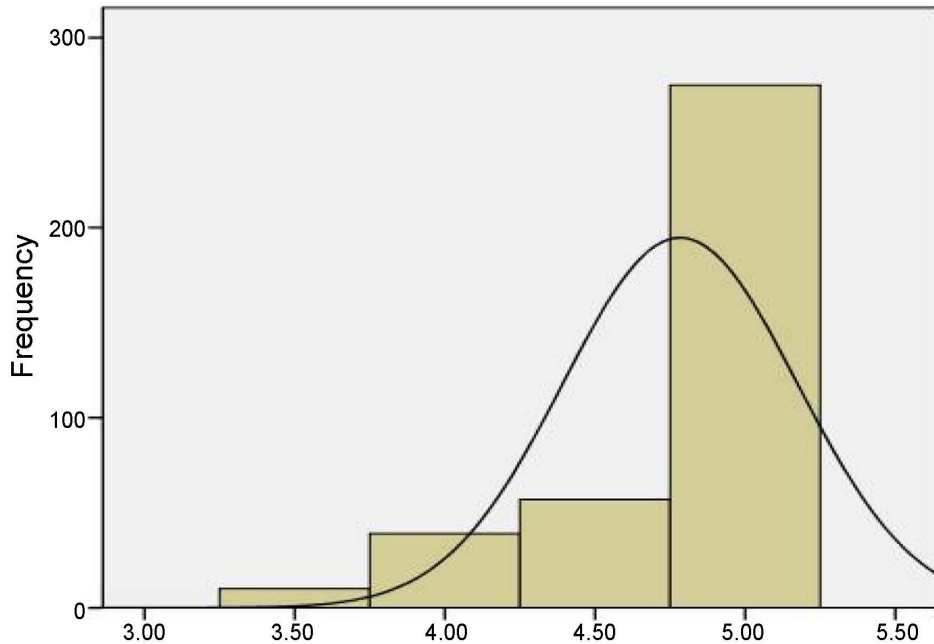

$\begin{aligned} \text { Mean } & =4.78 \\ & \end{aligned}$ Std. Dev. $=0.3$

Figure 1. Sample size 384, average: 0.39030, middle: 5.0000, standard division: 89.193 , minimum value: 89.193 , most value: 5.00 , test statistic: 89.193 , significance level: 0.000 , state variable: well suited and it has the first priority. 


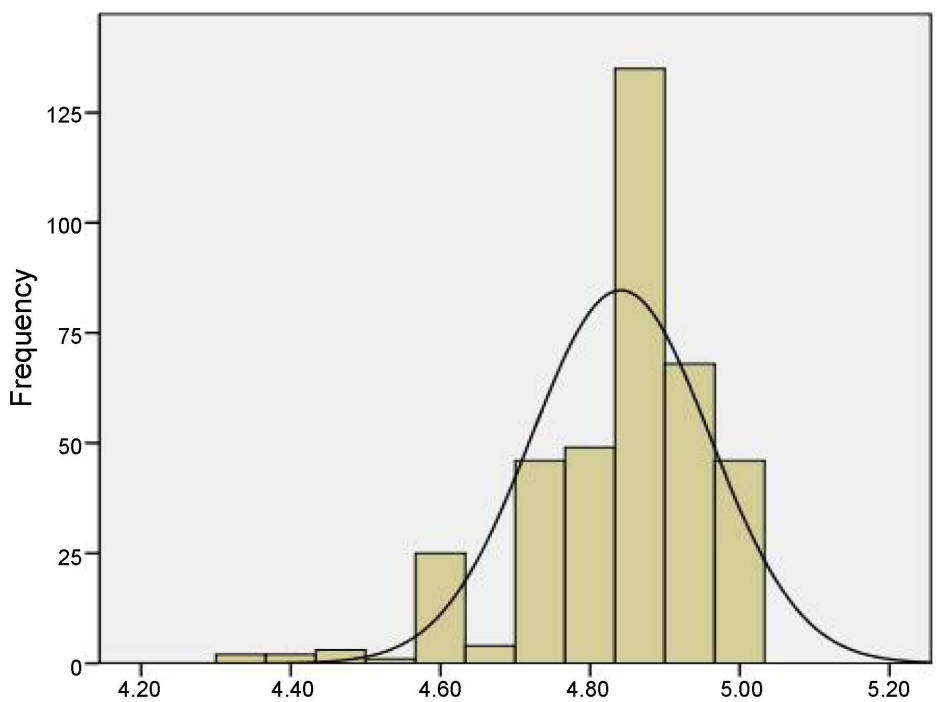

Mean $=4.84$ Std. Dev. $=0.12$ $\mathrm{N}=381$

Figure 2. Sample size 384, average: 4.8411, middle: 4.8667, standard division: 0.11965 , minimum value: 4.33 , most value: 5.00 , test statistic: 300.350 , significance level: 0.000 , state variable: well suited and it has the second priority.

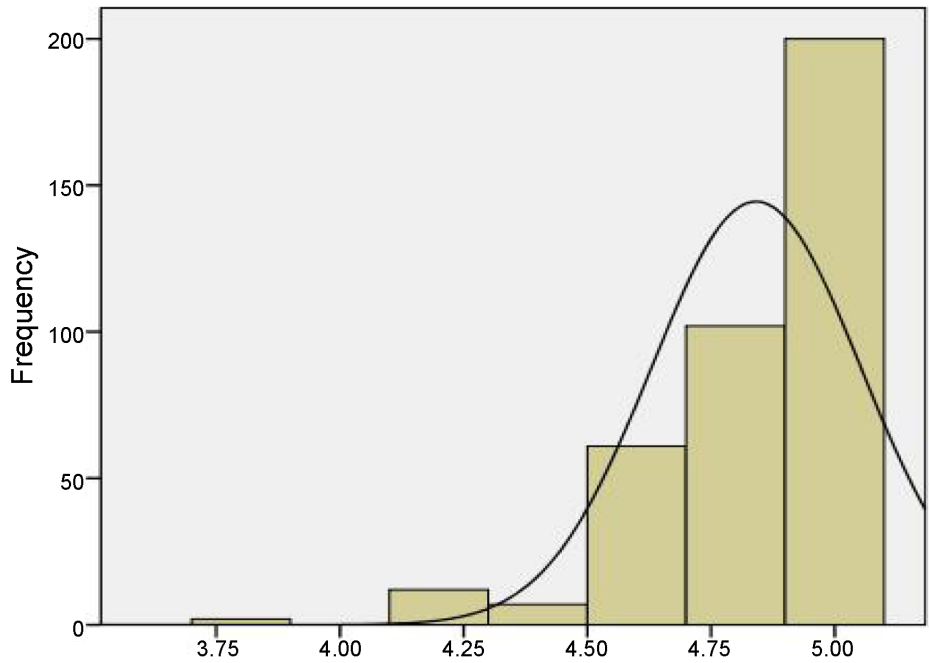

Mean $=4.84$ td. Dev. $=0.212$ $\mathrm{N}=384$

Figure 3. Sample size 384, average: 4.8411, middle: 5.0000, standard division: 0.21210 , minimum value: 3.80 , most value: 5.00 , test statistic: 170.103 , significance level: 0.000 , state variable: well suited and it has the third priority.

\subsubsection{Peaceful Co-Existence in Culture}

The assumption of normality related to Peaceful Co-Existence in Culture is shown in Figure 5.

\subsubsection{Peaceful Co-Existence in Jihad}

The assumption of normality related to Peaceful Co-Existence in Jihad is shown in Figure 6.

\subsubsection{Peaceful Co-Existence in Life}

The assumption of normality related to Peaceful Co-Existence in Life is shown in Figure 7.

The results of Analytical methods are shown in Table 3. 


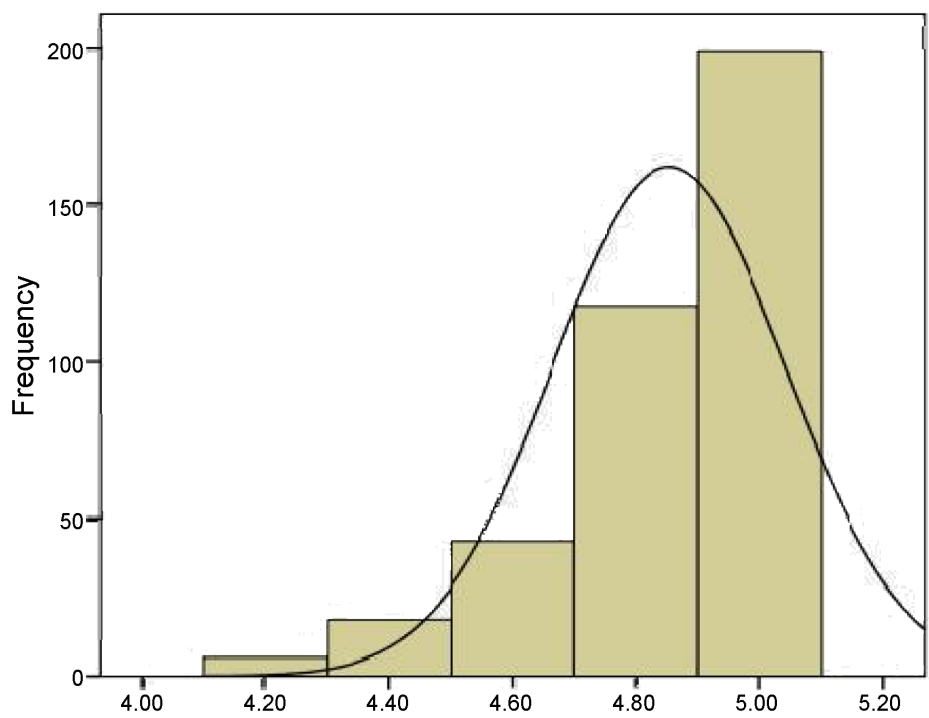

Mean $=4.85$ Std. Dev. $=0.189$ $\mathrm{N}=384$

Figure 4. Sample size 384, average: 4.8531 , middle: 5.0000, standard division: 0.18869 , minimum value: 4.20 , most value: 5.00 , test statistic: 192.452 , significance level: 0.000 , state variable: well suited and it has the forth priority.

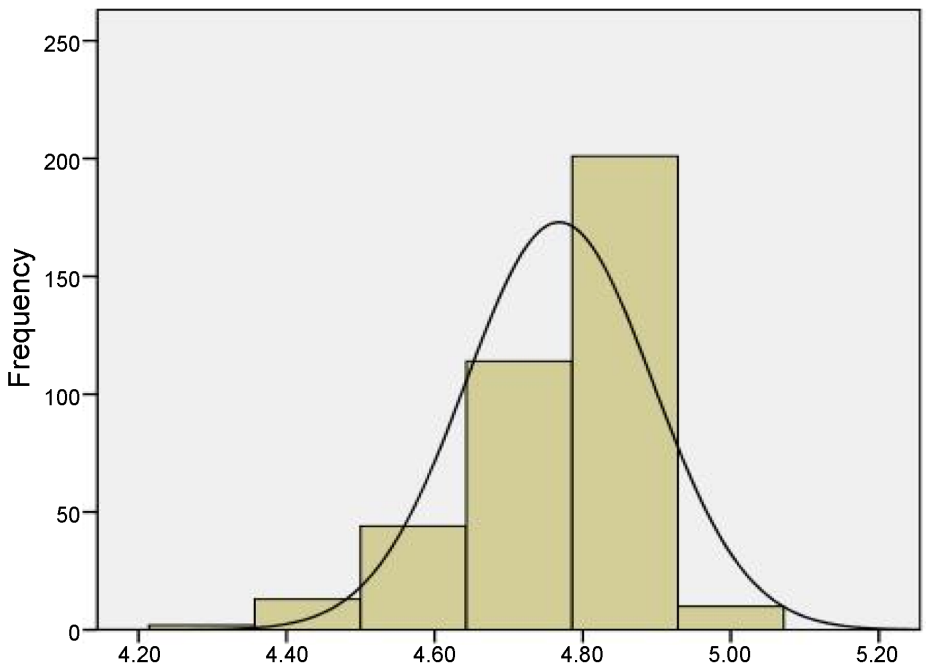

Mean $=4.77$ Std. Dev. $=0.126$
$N=384$

Figure 5. Sample size 384, average: 4.7682, middle: 4.8571, standard division: 0.12649 , minimum value: 4.29 , most value: 5.00 , test statistic: 273.944 , significance level: 0.000 , state variable: well suited and it has the fifth priority.

Test, Kolmogorov-Smirnov hypotheses are examined as follows: The observations follow the normal distribution; $\mathrm{H}_{0}$ the observations don't follow the normal distribution.

$\mathrm{H}_{1}$ : so given that the significance level is less than 0.05 for all variables, observations assumption of normality (null hypothesis) is rejected. In light of these observations follow a normal distribution, non-parametric methods are used to analyze the observations.

\subsection{Analytical Methods (Test, Kolmogorov-Smirnov)}

A one-sample student t-test for each of the variables: 


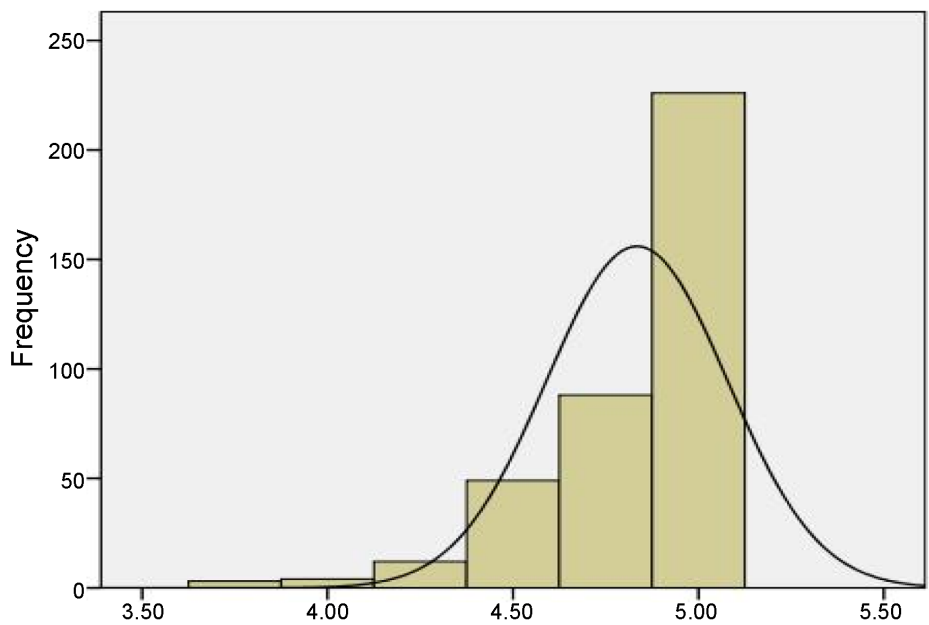

Mean $=4.83$ Std. Dev. $=0.24$ $\mathrm{N}=382$

Figure 6. Sample size 384, average: 4.8344, middle: 5.000, standard division: 0.24417 , minimum value: 3.75 , most value: 5.00 , test statistic: 6.699 , significance level: 0.000 , state variable: well suited and it has the sixth priority.

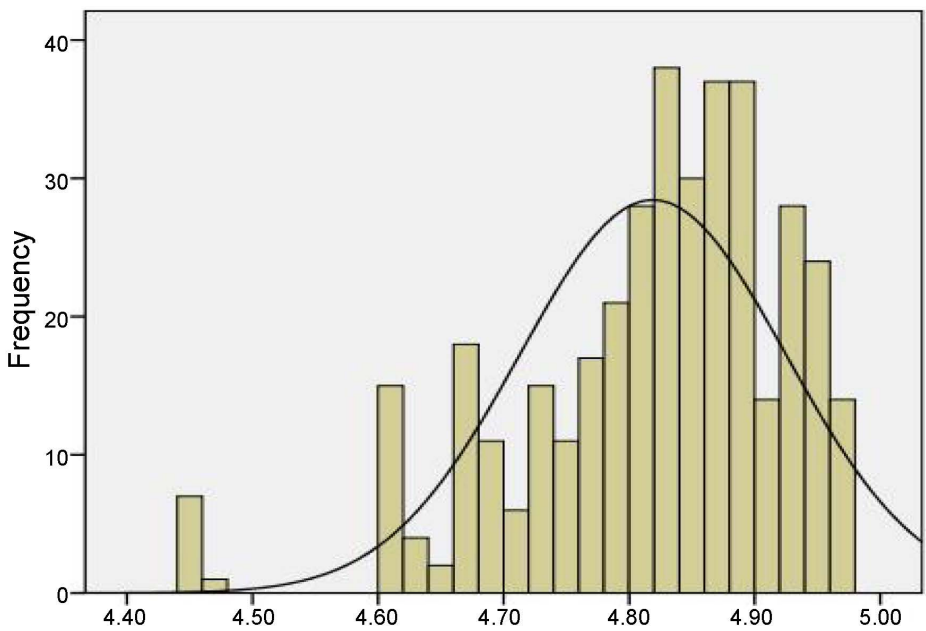

Figure 7. Sample size 384, average: 4.8189 , middle: 4.8345 , standard division: 0.10606 , minimum value: 4.45 , most value: 4.98 , test statistic: 2.193 , significance level: 0.000 , state variable: well suited and it has the seventh priority.

Table 3. Analytical methods (test, Kolmogorov-Smirnov).

\begin{tabular}{cccc}
\hline & & \multicolumn{2}{c}{ Test Kolmogorov-Smirnov } \\
\hline Variable name & Number & The test statistic & Significance level \\
\hline Peaceful co-existence in religion & 384 & 8.438 & 0.000 \\
Peaceful co-existence in society & 384 & 4.647 & 0.000 \\
Peaceful co-existence in science & 384 & 5.759 & 0.000 \\
Peaceful co-existence in economy & 384 & 5.880 & 0.000 \\
Peaceful co-existence in culture & 384 & 6.044 & 0.000 \\
Peaceful co-existence in Jihad & 384 & 6.699 & 0.000 \\
Peaceful co-existence in life & 384 & 2.193 & 0.000
\end{tabular}

This test compares the mean value of a variable with a fixed design. Given normality, the number of observations is larger than 30 , so we use verify the as- 
sumption of a one-sample Student's t-test (Table 4).

P-value obtained at confidence level of 95 percent for all the parameters compared with the value 0.05 . This value is less than the error (0.05), and then the hypothesis $\mathrm{H}_{0}$ is rejected. The confidence interval is positive for anyone.

$\mathrm{P}$-value obtained at confidence level of 95 percent for all the parameters compared with the value 0.05 . This value is less than the error (0.05), and then the hypothesis $\mathrm{H}_{0}$ is rejected. The confidence interval is positive for anyone (Table 5 \& Table 6).

\section{Findings}

There are so many convenient advantages in the essence of peaceful co-existence in religious sphere regarding Christian life in Tehran. It has number one priority among other spheres. There is remarkable attention in essence of peaceful coexistence in social sphere regarding Christian existence and it has number two priority. Scientific, cultural, economic and Jihad spheres have subsequence priorities. As a conclusion, they satisfy the living in the light of Islamic government

Table 4. Comparison test with constant.

\begin{tabular}{ccccccccc}
\hline Variable name & $\begin{array}{c}\text { Sample } \\
\text { size }\end{array}$ & Average & $\begin{array}{c}\text { Standard } \\
\text { deviation }\end{array}$ & $\begin{array}{r}\text { T test } \\
\text { statistic }\end{array}$ & $\begin{array}{r}\mathrm{P} \\
\text { value }\end{array}$ & $\begin{array}{r}\text { Lower } \\
\text { bound }\end{array}$ & $\begin{array}{c}\text { Upper } \\
\text { bound }\end{array}$ & $\begin{array}{c}\text { State } \\
\text { variable }\end{array}$ \\
\hline Peaceful co-existence & 384 & 4.818 & 0.10606 & 333.4 & 0.000 & 1.808 & 1.82 & Well suited \\
\hline
\end{tabular}

Table 5. Comparison test with constant.

\begin{tabular}{cccccccccc}
\hline Variable name & $\begin{array}{c}\text { Sample } \\
\text { size }\end{array}$ & Average & $\begin{array}{c}\text { Standard } \\
\text { deviation }\end{array}$ & $\begin{array}{c}\text { T test } \\
\text { statistic }\end{array}$ & p value $\begin{array}{c}\text { LowerUpper } \\
\text { boundbound }\end{array}$ & $\begin{array}{c}\text { State } \\
\text { variable }\end{array}$ \\
\hline $\begin{array}{c}\text { Peaceful co-existence in } \\
\text { religion }\end{array}$ & 384 & 0.39030 & 89.193 & 89.193 & 0.000 & 1.74411 .822 & Well suited \\
$\begin{array}{c}\text { Peaceful co-existence in } \\
\text { society }\end{array}$ & 384 & 0.11965 & 300.350 & 300.35 & 0.000 & 1.82911 .853 & Well suited \\
$\begin{array}{c}\text { Peaceful co-existence in } \\
\text { science }\end{array}$ & 384 & 0.21210 & 170.103 & 170.10 & 0.000 & 1.81991 .862 & Well suited \\
$\begin{array}{c}\text { Peaceful co-existence in } \\
\text { economy }\end{array}$ & 384 & 0.18869 & 192.452 & 192.45 & 0.000 & 1.8342 & 1.872 & Well suited \\
$\begin{array}{c}\text { Peaceful co-existence in } \\
\text { culture }\end{array}$ & 384 & 0.12649 & 273.944 & 273.94 & 0.000 & 1.75551 .780 & Well suited \\
Peaceful co-existence in Jihad & 384 & 0.24417 & 146.838 & 146.83 & 0.000 & 1.8590 & 1.859 & Well suited
\end{tabular}

Table 6. Following order of priorities ranking.

\begin{tabular}{ccc}
\hline Variable name & Average rating & Priority \\
\hline Peaceful co-existence in religion & 3.99 & First Priority \\
Peaceful co-existence in society & 3.73 & Second Priority \\
Peaceful co-existence in science & 3.65 & Third Priority \\
Peaceful co-existence in economy & 3.64 & Fourth Priority \\
Peaceful co-existence in culture & 3.46 & Fifth Priority \\
Peaceful co-existence in Jihad & 2.53 & Sixth Priority \\
\hline
\end{tabular}


in all-aspect life engagement [10]. Adequate interaction and abundant respect can be observed between various religious groups. Researchers suggest more tolerance and harmony among different religious followers in all dimensions of society.

\section{References}

[1] Jabarouti, R., Shariat, A. and Shariat, A. (2014) Effect of Persian Classic Poetry on the Level of Stress Hormone in Retired Academicians. Journal of Poetry Therapy, 27, 25-33. https://doi.org/10.1080/08893675.2014.871809

[2] Ali, M.M. (2011) Holy Quran. Ahmadiyya Anjuman Ishaat Islam Lahore USA.

[3] Al-Bukhari, M.I.I. (1986) The Translation of the Meanings of Sahih Al-Bukhari. Kazi Publications, Tehran, Iran.

[4] Vos, T., Barber, R.M., Bell, B., Bertozzi-Villa, A., Biryukov, S., Bolliger, I., Charlson, F., Davis, A., Degenhardt, L. and Dicker, D. (2015) Global, Regional, and National Incidence, Prevalence, and Years Lived with Disability for 301 Acute and Chronic Diseases and Injuries in 188 Countries, 1990-2013: A Systematic Analysis for the Global Burden of Disease Study 2013. The Lancet, 386, 743-800.

https://doi.org/10.1016/S0140-6736(15)60692-4

[5] Badawi, G.A. (1976) Polygamy in Islamic Law. Muslim Students' Association.

[6] Murad, A.H., Badawi, M. and Hutchinson, U. (2000) The Majestic Quran: An English Rendition of Its Meanings. Nawawi Foundation, Chicago, IL.

[7] Kazmi, S.W. (2005) Role of Education in Globalization: A Case for Pakistan. SAARC Journal of Human Resource Development, 1, 90-107.

[8] Diez, M. (2014) Three Directions to Explore the Quran. OASIS, 20, 116.

[9] Shariat, A., Tamrin, S.B., Arumugam, M., Danaee, M. and Ramasamy, R. (2016) Comparative Reliability of Different Instruments Used to Measure the Severity of Musculoskeletal Disorders in Office Workers. Work, 54, 753-758.

[10] Zayid, M. (1980) The Quran: An English Translation of the Meaning of the Quran. Dar Al-Choura.

Submit or recommend next manuscript to OALib Journal and we will provide best service for you:

- Publication frequency: Monthly

- 9 subject areas of science, technology and medicine

- Fair and rigorous peer-review system

- Fast publication process

- Article promotion in various social networking sites (LinkedIn, Facebook, Twitter, etc.)

- Maximum dissemination of your research work

Submit Your Paper Online: Click Here to Submit

Or Contact service@oalib.com 